\title{
Fermentation of polyethylene glycol via acetaldehyde in Pelobacter venetianus
}

\author{
Axel Straß and Bernhard Schink \\ Fakultät für Biologie, Universität Konstanz, Postfach 5560, D-7750 Konstanz, Federal Republic of Germany
}

Summary. Pelobacter venetianus, a strictly anaerobic bacterium recently isolated with polyethylene glycol (PEG) as substrate, ferments PEG's with molecular masses of $106-40000$, as well as acetoin, ethanolamine, choline, and ethoxyethanol, to acetate and ethanol. Ethylene glycol (EG) and acetaldehyde were fermented in the same manner at limiting concentrations in continuous culture. Growth with glycolaldehyde led to acetate as sole fermentation product. Acetaldehyde appeared as byproduct of PEG fermentation, and accumulated to high concentrations during degradation of PEG 4000 and PEG 6000 . Utilization of PEG's was constitutive, whereas acetoin degradation was inducible. Acetaldehyde was shown to be the primary product of EG degradation, and inhibited utilization of other substrates. Enzymes involved in the fermentation of PEG, $\mathrm{EG}$, acetoin, and glycolaldehyde were demonstrated in cell-free extracts, except for the PEG degrading enzyme and EG dehydrase. These results demonstrate that acetaldehyde plays a central role in the metabolism of Pelobacter venetianus. A scheme of intermediary metabolism and PEG degradation is discussed.

\section{Introduction}

Polyethylene glycol (PEG) is a synthetic watersoluble polyether of the common structural for-

Offprint requests to: Bernhard Schink, Fachbereich Biologie Mikrobiologie, Philipps-Universität, Lahnberge, D-3550 Marburg, Federal Republic of Germany

Abbreviations: EG: ethylene glycol, Di-EG: diethylene glycol; PEG (20000): polyethylene glycol (molecular weight 20000) mula $\mathrm{H}\left(\mathrm{OCH}_{2} \mathrm{CH}_{2}\right)_{\mathrm{n}} \mathrm{OH}$. PEG's with molecular weights from 106 to 20000 are applied in the manufacturing of lubricants, cosmetics, pharmaceuticals and antifreeze agents, and are hydrophilic constituents of a broad variety of nonionic surfactants (Cox 1978; Bock and Stache 1982). Information on their biodegradation is sparse and often contradictory.

The central problem of PEG degradation is the cleavage of an aliphatic ether linkage. Several authors have observed a primary dehydrogenation to the aldehyde or carboxylic acid derivative (Kawai et al. 1983, 1984; Watson and Jones 1977; Payne and Todd 1966), but it remained unclear how the C-2 moiety is released. Primary desaturation and hydration to a halfacetal derivative would allow the release of an aldehyde unit (Thélu et al. 1980). Hydrolytic cleavage of PEG to mono- and oligomers by an extracellular hydrolase was described for a Pseudomonas isolate (Haines and Alexander 1975). These results could never be reproduced, however, and the original strain was lost. Evidence of a new type of ethercleaving enzyme was recently provided by Kawai (1985).

Degradation of PEG in the absence of molecular oxygen was reported for a nitrate-reducing bacterium (Grant and Payne 1983) and for fermenting bacteria (Dwyer and Tiedje 1983; Schink and Stieb 1983). A new Gram-negative, strict anaerobe, Pelobacter venetianus, was described, which completely degraded PEG of molecular weights from 106 to 20,000 to acetate and ethanol (Schink and Stieb 1983). This bacterium also grew with some nonionic surfactants, acetoin, and some 1,2-diols, but could not grow with the monomer ethylene glycol (EG). It was assumed that acetaldehyde is an intermediate in PEG degradation in this organism as this was first suggested 
for PEG degradation by an aerobic Acinetobacter strain (Pearce and Heydeman 1980).

The present study was initiated to examine whether acetaldehyde is involved in PEG degradation by Pelobacter venetianus. Furthermore, the enzymes involved in PEG fermentation and the role of EG in the metabolism of this bacterium were of interest.

\section{Materials and methods}

Microorganism. Pelobacter venetianus strain GraPEG1, DSM 2394 was cultivated in saltwater mineral medium at $28^{\circ} \mathrm{C}$ as described previously (Schink and Stieb 1983). Growth experiments were performed in 20-ml screw cap tubes sealed with either aluminum caps or butyl rubber septa (Bellco, Vineland, USA). Growth was followed by direct insertion of culture tubes into a Bausch and Lomb Spectronic 70 spectrophotometer.

Continuous culture experiments were carried out at $24^{\circ} \mathrm{C}$ in a magnetically stirred $300-\mathrm{ml}$ Erlenmeyer flask sealed with a rubber stopper without headspace. The growth medium was kept under $\mathrm{N}_{2} / \mathrm{CO}_{2}$ mixture $(80 \% / 20 \%)$ and passed a peristaltic pump and a gassed dropping vial right on top of the culture vessel. The cell suspension left the culture vessel via a short, narrow tubing from which also samples for analysis were taken, and was collected in a reservoir connected to a KOH-containing gas washing bottle to trap aldehyde derivatives.

Enzyme assays. All enzyme activities were determined at $25^{\circ} \mathrm{C}$ in a Zeiss PM 4 spectrophotometer using rubber-stoppered $\mathrm{N}_{2}$-gassed cuvettes. Enzymes of the intermediary metabolism were assayed in French pressure cell extracts as previously described (Schink 1985). Conversion of 1,2-diols and polyethylene glycols to acetaldehyde was assayed either with cell-free extracts or with cell suspensions permeabilized by cetyltrimethylammonium bromide within the cuvette. The techniques applied were taken from the dehydrase literature (Abeles 1966; Toraya and Fukui 1982; Schütz and Radler 1984).

Chemical assays. Polyethylene glycol was determined according to Stevenson (1954). Alcohols, fatty acids, and acetaldehyde were assayed by gas chromatography as described previously (Schink and Pfennig 1982); for determination of acetaldehyde, a lower oven temperature $\left(90^{\circ} \mathrm{C}\right)$ was used.

Protein was quantified by a microbiuret method (Kuenen and Veldkamp 1972).

Chemicals. All chemicals used were of reagent grade quality and obtained from Fluka, Buchs, Switzerland, and Merck, Darmstadt, West Germany. Biochemicals were provided by Boehringer, Mannheim, and Sigma, München, West Germany. Polyethylene glycols were products of Serva, Heidelberg, and Fluka, Buchs.

\section{Results}

\section{Utilization of new substrates}

To obtain further information on the pathway of polyethylene glycol degradation in Pelobacter ven- etianus, further substrates were checked in batch culture for possible utilization. Ethanolamine and choline both supported growth, and were fermented to acetate and ethanol. Ethylene glycol, acetaldehyde, and glycolaldehyde were also fermented with concomitant increase in cell density, however, only if added at low concentrations $(\leq 5 \mathrm{mM})$ to comparably dense cell suspensions $\left(\mathrm{OD}_{650} \geq 0.20\right)$. At higher concentrations, these three substrates did not support growth but inhibited also utilization of other substrates.

$P$. venetianus was grown with EG and acetaldehyde in continuous culture. The results presented in Table 1 were obtained in two separate experiment series in which Di-EG was provided as a background substrate to which either EG or acetaldehyde was added. Both EG and acetaldehyde were fermented to nearly equal amounts of acetate and ethanol; with EG, also a trace of acetaldehyde was formed. The cell yield was $4.0-$ $5.0 \mathrm{~g}$ dry matter per mol EG and $2.0-3.0 \mathrm{~g}$ per mol acetaldehyde at 7.4 and $24 \mathrm{~h}$ residence time, respectively. The cell yield obtained with glycolaldehyde fermentation to acetate in batch culture experiments was $4.5-5.2 \mathrm{~g}$ per mol. P. venetianus was not able to ferment dimethoxyethane or tetraethyleneglycol dimethylether whereas ethoxyethanol supported growth (see Schink and Stieb 1983).

\section{Degradation of various PEG's}

PEG of various molecular weights was tested for degradation by $P$. venetianus. All polymers from the dimer to PEG 40,000 were degradable (Table 2), most of them with stoichiometric formation of acetate and ethanol. The growth yields were in the range of $2.7-5.0 \mathrm{~g} \cdot \mathrm{mol}^{-1}$. Incomplete substrate degradation was observed with PEG's $400-1000$ and, more pronounced, with PEG's 4000-6000. With the latter two polymers, yields were extremely low, and considerable amounts of acetaldehyde $(1.5-2.5 \mathrm{mM})$ accumulated in the medium, no matter if the substrate solutions were autoclaved or filter sterilized, or if substrates obtained from different manufacturers were used.

The doubling times of $P$. venetianus cultures during growth with various PEG's varied between $4.25 \mathrm{~h}$ with Tri-EG, and $7.8 \mathrm{~h}$ with PEG 20,000. If cells pregrown with acetoin were transferred into subcultures with Tri-EG or PEG 20,000 as substrates, they immediately started to grow exponentially. Cells precultivated with Tri-EG always exhibited a lag phase of about $24 \mathrm{~h}$ after transfer 
Table 1. Stoichiometry of substrate conversion and cell yield formation by Pelobacter venetianus grown in continuous culture with ethylene glycol or acetaldehyde as substrates

\begin{tabular}{|c|c|c|c|c|c|c|c|}
\hline \multirow[t]{2}{*}{ Substrate $^{a}$} & \multirow{2}{*}{$\begin{array}{l}\text { Concen- } \\
\text { tration }\end{array}$} & \multicolumn{3}{|c|}{ Products formed ${ }^{b}$} & \multirow{2}{*}{$\begin{array}{l}\text { Gros }^{\mathrm{c}} \\
\mathrm{OD}_{650}\end{array}$} & \multirow{2}{*}{$\begin{array}{l}\mathrm{Net}^{\mathrm{c}} \\
\mathrm{OD}_{650}\end{array}$} & \multirow{2}{*}{$\begin{array}{l}Y^{\mathrm{d}} \\
\mathrm{g} / \mathrm{mol}\end{array}$} \\
\hline & & $\begin{array}{l}\text { Acetal- } \\
\text { dehyde }\end{array}$ & Ethanol & Acetate & & & \\
\hline \multirow[t]{4}{*}{$\mathrm{EG}$} & 0 & 1.0 & 11.0 & 7.2 & 0.11 & - & - \\
\hline & 2 & 1.3 & 11.7 & 7.8 & 0.14 & 0.03 & 5.0 \\
\hline & 5 & 1.2 & 13.5 & 8.9 & 0.17 & 0.06 & 4.0 \\
\hline & 10 & 0.8 & 16.9 & 11.6 & 0.24 & 0.13 & 4.35 \\
\hline \multirow[t]{5}{*}{ Acetaldehyde } & 0 & $<0.1$ & 4.5 & 5.3 & 0.065 & - & - \\
\hline & 5 & $<0.1$ & 6.4 & 6.8 & 0.085 & 0.02 & 1.34 \\
\hline & 10 & $<0.1$ & 8.7 & 10.5 & 0.130 & 0.065 & 2.1 \\
\hline & 15 & $<0.1$ & 10.9 & 12.9 & 0.170 & 0.105 & 2.34 \\
\hline & 20 & $<0.1$ & 14.1 & 15.6 & 0.230 & 0.165 & 2.7 \\
\hline
\end{tabular}

a The experiments with EG as substrate were carried out at a residence time of $7.4 \mathrm{~h}$ with $10 \mathrm{mM}$ Di-EG as background substrate to which EG was added to the concentrations indicated. In the experiments with acetaldehyde as substrate, the residence time was $24 \mathrm{~h}$ with $5 \mathrm{mM}$ Di-EG as background substrate

b Total products formed from both Di-EG and the respective additional substrate

c Gross and net OD differ by the background density reached without additional substrate

d Molar growth yields were calculated from optical densities via a conversion factor $\left(\mathrm{OD}_{650} \cong 33.5 \mathrm{mg}\right.$ dry cell matter $\left.\cdot \mathrm{I}^{-1}\right)$ which was determined in separate batch culture experiments with 1-1 cultures

Table 2. Growth yields and stoichiometry of PEG fermentation by $P$. venetianus

\begin{tabular}{|c|c|c|c|c|c|c|c|c|}
\hline \multirow[t]{2}{*}{ Substrate } & \multirow{2}{*}{$\begin{array}{l}\text { Amount } \\
\text { per liter }\end{array}$} & \multirow{2}{*}{$\begin{array}{l}\mathrm{OD}_{650} \\
\text { reached }\end{array}$} & \multirow{2}{*}{$\begin{array}{l}\text { Substrate } \\
\text { provided } \\
(\mu \mathrm{mol})^{\mathbf{a}}\end{array}$} & \multicolumn{3}{|c|}{ Products $(\mu \mathrm{mol})$} & \multirow{2}{*}{$\begin{array}{l}\text { Growth } \\
\text { yield } \\
\mathrm{g} \cdot \mathrm{mol}^{-1 \mathrm{~b}}\end{array}$} & \multirow{2}{*}{$\begin{array}{l}\text { Electron } \\
\text { recovery } \\
\%\end{array}$} \\
\hline & & & & Acetaldehyde & Ethanol & Acetate & & \\
\hline Di-EG & $10.0 \mathrm{mmol}$ & 0.25 & 400 & 2 & 190 & 174 & 4.2 & 105 \\
\hline Tri-EG & $6.7 \mathrm{mmol}$ & 0.3 & 400 & 2 & 184 & 178 & 5.0 & 107 \\
\hline PEG 200 & $1.0 \mathrm{~g}$ & 0.21 & 412 & 7 & 158 & 173 & 3.4 & 92 \\
\hline PEG $\quad 400$ & $1.0 \mathrm{~g}$ & 0.16 & 430 & 5 & 123 & 168 & 2.3 & 74 \\
\hline PEG 1000 & $1.0 \mathrm{~g}$ & 0.25 & 446 & 6 & 158 & 185 & 3.6 & 84 \\
\hline PEG 1540 & $1.0 \mathrm{~g}$ & 0.23 & 448 & 4 & 146 & 161 & 3.4 & 78 \\
\hline PEG 4000 & $1.0 \mathrm{~g}$ & 0.05 & 452 & 44 & 14 & 9 & $(0.07)$ & 15 \\
\hline PEG 6000 & $1.0 \mathrm{~g}$ & 0.06 & 455 & 25 & 30 & 13 & $(0.08)$ & 15 \\
\hline PEG 10000 & $1.0 \mathrm{~g}$ & 0.175 & 455 & 7 & 154 & 171 & 2.7 & 80 \\
\hline PEG 20000 & $1.0 \mathrm{~g}$ & 0.25 & 455 & 2 & 180 & 198 & 3.8 & 94 \\
\hline PEG 40000 & $1.0 \mathrm{~g}$ & 0.24 & 455 & 2 & 176 & 190 & 3.5 & 92 \\
\hline
\end{tabular}

Experiments were carried out in 4-8 parallels in $20 \mathrm{ml}$ Bellco tubes with screw caps

a Substrate provided was calculated as EG monomers

b Growth yields were calculated via cell density and an experimentally determined conversion factor $\left(\mathrm{OD}_{650}=0.1\right.$ refers to 33.5 mg dry matter $\cdot 1^{-1}$ )

c Total electron recovery also includes the amount of electrons assimilated, calculated by the equation $19 \mathrm{C}_{2} \mathrm{H}_{6} \mathrm{O}_{2}+8 \mathrm{HCO}_{3}^{-}$ $\rightarrow 6\left\langle\mathrm{C}_{4} \mathrm{H}_{7} \mathrm{O}_{4}\right\rangle+11 \mathrm{CH}_{3} \mathrm{COO}^{-}+3 \mathrm{H}^{+}+22 \mathrm{H}_{2} \mathrm{O}$

to fresh medium with acetoin as substrate. It appears that the PEG-degrading enzyme(s) is constitutive whereas the acetoin-degrading one is inducible.

\section{The role of acetaldehyde}

Acetaldehyde always appeared in traces $(0.1-$ $0.3 \mathrm{mM}$ ) as a byproduct of degradation of PEG, acetoin, ethanolamine, and ethoxyethanol. Higher amounts of acetaldehyde accumulated if the substrates were provided at enhanced concentrations. With Di-EG as substrate, up to $7 \mathrm{mM}$ acetaldehyde was measured in the medium. This effect was less pronounced with PEG 20,000. In fresh cell-free extracts prepared from cells growing exponentially with $10 \mathrm{mM}$ Di-EG, up to $9.3 \mathrm{mM}$ acetaldehyde was detected when the growth medium only contained $0.1-0.2 \mathrm{mM}$ acetaldehyde. 


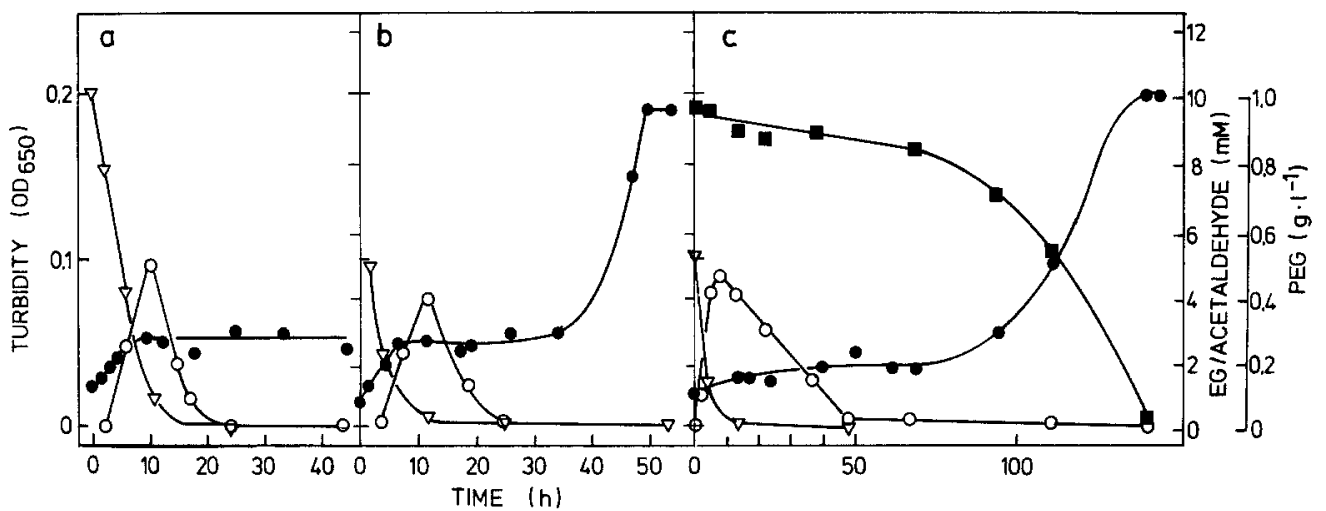

Fig. 1. Transformation of EG in batch cultures of Pelobacter venetianus. a $5 \mathrm{mM}$ EG as sole substrate; b $10 \mathrm{mM}$ Di-EG plus $5 \mathrm{mM}$ EG; c $0.1 \%$ PEG 20000 plus 5 mM EG. Symbols: ( $\nabla)$ EG, (O) acetaldehyde, ( $)$ PEG 20000, (○) optical density

Table 3. Enzymes detected in crude cell extracts of Pelobacter venetianus ${ }^{\mathrm{a}}$

\begin{tabular}{|c|c|c|c|c|}
\hline \multirow[t]{2}{*}{ Enzyme } & \multirow[t]{2}{*}{ EC No. } & \multicolumn{2}{|c|}{ Cells grown with } & \multirow[t]{2}{*}{ Acetoin } \\
\hline & & Di-EG & PEG 20000 & \\
\hline 2,3-Butanediol dehydrogenase & 1.1.1.4 & 0.015 & $<0.001$ & 1.2 \\
\hline Acetoin dehydrogenase & 1.1.1.5 & 0.07 & 0.009 & 0.950 \\
\hline \multicolumn{5}{|l|}{ Alcohol dehydrogenase $e^{b}$} \\
\hline with acetaldehyde & & 0.47 & 0.910 & 1.05 \\
\hline with glycolaldehyde & & 0.047 & 0.103 & 0.087 \\
\hline \multicolumn{5}{|l|}{ Acetaldehyde-Ferredoxin } \\
\hline -oxidoreductase $\mathrm{c}^{\mathrm{c}}$ & $?$ & 8.4 & 2.3 & 1.8 \\
\hline \multicolumn{5}{|l|}{ Pyruvate-Ferredoxin } \\
\hline -oxidoreductase ${ }^{c}$ & 1.2.7.1 & 0.063 & 0.04 & 0.13 \\
\hline Hydrogenase $^{\mathrm{c}}$ & 1.18 .99 .1 & 0.28 & 0.25 & 0.48 \\
\hline Phosphate acetyltransferase & 2.3.1.8 & 7.7 & 7.9 & 0.92 \\
\hline Acetate kinase & 2.7.2.1 & 2.2 & 0.47 & 0.30 \\
\hline
\end{tabular}

a Numbers give international units of enzyme activities $\left(\mu \mathrm{mol} \cdot \mathrm{min}^{-1} \cdot \mathrm{mg}\right.$ protein $\left.{ }^{-1}\right)$ assayed in crude cell extracts

b Assayed as NADH-dependent aldehyde reduction

c Assayed as substrate-dependent reduction of benzyl viologen

d After International Union of Biochemistry (1984)

Acetaldehyde formation was most conspicuous with EG as substrate. Cell suspensions provided with $10 \mathrm{mM}$ EG did not grow with this substrate but accumulated acetaldehyde up to $5 \mathrm{mM}$ in the medium (Fig. 1a). If EG was given together with a further substrate, it was immediately converted to acetaldehyde which was only slowly degraded (Fig. 1b, c). Utilization of the additional substrate and growth started only after the acetaldehyde disappeared. Similar results were obtained with ethanolamine and acetoin as additional substrates, or if acetaldehyde instead of EG was added to growing cultures (not shown). It is concluded that $P$. venetianus has a constitutive EG-dehydrating enzyme, and that the accumulated reaction product, acetaldehyde, prevents degradation of other substrates until it itself is decomposed.
Enzymes involved in intermediary metabolism

Enzymatic activities were assayed in crude extracts of cells grown with Di-EG, PEG 20,000, and acetoin (Table 3). 2,3-Butanediol dehydrogenase and acetoin dehydrogenase both were detected only in acetoin-grown cells. The alcohol dehydrogenase present reacted also with glycolaldehyde.

Numerous attempts were made to assay for a PEG-degrading or EG-dehydrating enzyme. Experiments were performed with crude extracts as well as with cells permeabilized with cetyltrimethylammonium bromide. Reproducible aldehyde formation could only be demonstrated with intact cells, never with cell extracts or permeabilized cells. Addition of various reducing agents, cobalt chloride, potassium chloride, ammonium sul- 
phate, magnesium chloride, ethylene diamine tetraacetate or coenzyme $B_{12}$ were without effect as well.

\section{Discussion}

The ability to degrade PEG is a property only rarely found among anaerobic bacteria. In a screening programme among a broad variety of anaerobes, we could not find any other strain able to grow with this substrate (MW 106-20,000) except those which were originally enriched with it (Grant and Payne 1983; Dwyer and Tiedje 1983; Schink and Stieb 1983).

The present study revealed that $P$. venetianus forms acetaldehyde during degradation of various PEGs, glycolaldehyde, EG, acetoin, and ethanolamine, and that acetaldehyde can also serve as sole substrate for growth if provided at low concentrations. At enhanced concentrations, acetaldehyde inhibits growth and utilization of other substrates. On the basis of enzymatic studies, a scheme of the metabolism of $P$. venetianus is proposed in which acetaldehyde plays a central role (Fig. 2). Oxidation of acetaldehyde leads via acetyl-CoA and acetyl phosphate to acetate, and energy is conserved in the acetate kinase reaction. Reduction of acetaldehyde with NADH leads to ethanol; the alcohol dehydrogenase activity de-

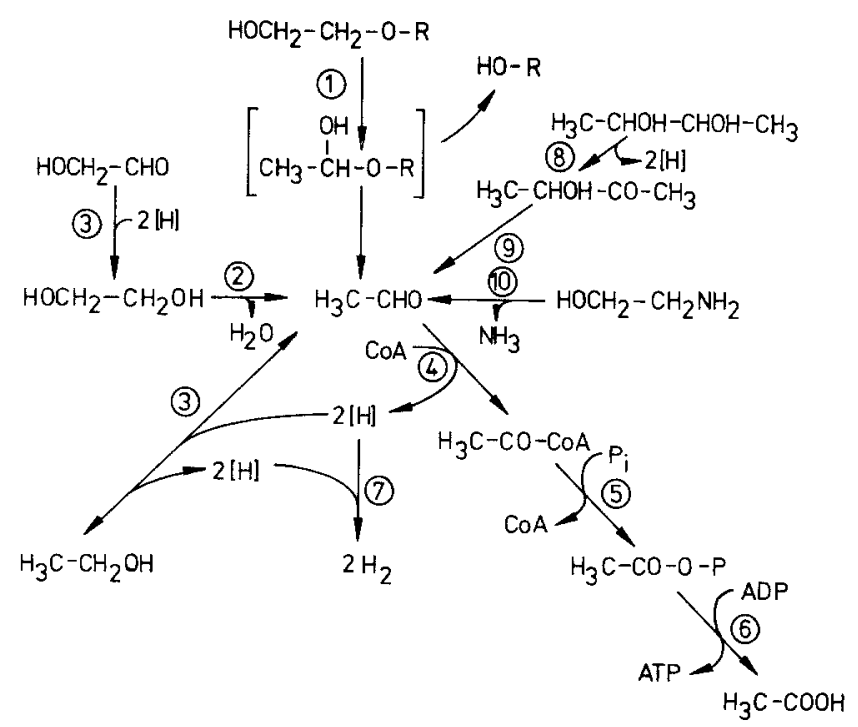

Fig. 2. Scheme of intermediary metabolism of Pelobacter venetianus. Enzymes: 1. PEG degrading enzyme, 2. diol dehydrase, 3. alcohol dehydrogenase, 4 . aldehyde ferredoxin oxidoreductase, 5. phosphate acetyltransferase, 6 . acetate kinase, 7. hydrogenase, 8. 2,3-butanediol dehydrogenase, 9. acetoin dehydrogenase, 10. ethanolamine ammonia lyase tected also reduced glycolaldehyde to EG, however, at a considerably lower rate. Conversion of EG and PEG to acetaldehyde was only observed with suspensions of intact cells. Despite numerous attempts, we could not demonstrate the enzymes involved in these conversions in cell-free extracts or permeabilized cells. It appears probable that at least the EG dehydrase is a coenzyme $B_{12}$-dependent diol dehydrase as described for other bacteria (Abeles 1966; Barker 1972; Toraya and Fukui 1982). Since such an enzyme converts EG to acetaldehyde by exchanging a hydroxyl and a hydrogen residue at the two carbon atoms, the same enzyme could also catalyse PEG degradation by shifting the hydroxyl group from the terminal to the subterminal carbon atom. The halfacetal thus formed would easily release free acetaldehyde. Degradation of PEG by $P$. venetianus therefore would always require a free terminal hydroxyl group. This hypothesis is corroborated by the fact that this organism did not grow with tetraethyleneglycol dimethylether in which both terminal hydroxyl groups are masked, but degrades ethoxyethanol which has one free hydroxyl group. Anaerobic enrichment cultures with tetraethylenglycol dimethylether did not yield any bacterial growth over more than three months of incubation. This suggests that the above hypothesis is true also for other anaerobic bacteria, and that anaerobic splitting of aliphatic ether linkages requires the presence of a free hydroxyl group at the carbon atom vicinal to the ether-binding carbon.

EG was preferentially dehydrated by EG dehydrase and converted to acetaldehyde, which prevented utilization of other substrates. Originally we thought that lack of EG utilization and blocking of PEG utilization by EG were due to a transport effect (Schink and Stieb 1983). Both acetaldehyde and EG support growth of $P$. venetianus in continuous culture. The growth yields obtained $(2.0-5.0 \mathrm{~g}$ dry matter per mol) agree with the assumption that $1 \mathrm{~mol}$ ATP is formed during fermentation of $2 \mathrm{~mol}$ substrate ( $Y_{\text {ATP }}$ $10 \mathrm{~g} \cdot \mathrm{mol}^{-1}$ or less; Stouthamer 1979). Glycolaldehyde is probably metabolized via EG and acetaldehyde.

The findings that acetaldehyde accumulates in the cytoplasm during Di-EG and PEG degradation, and that EG dehydrase and "PEG lyase" were inactivated by cell disintegration both support the hypothesis that both EG and PEG are converted to acetaldehyde in the cytoplasm. This raises again the question how a huge synthetic polymer with molecular weights up to $40,000 \mathrm{D}$ can 
enter the cell. Preliminary studies have so far given no evidence to suggest the presence of any unusual porins in the outer membrane of $P$. venetianus (R. Benz, Konstanz; personal communication).

The finding that anaerobic degradation of PEG can only start from the free hydroxyl group at the end of the molecule is of major importance for anaerobic degradation of nonionic tensides. Aerobic degradation of these compounds begins with $\mathrm{O}_{2}$-dependent cleavage of the lipophilic from the hydrophilic PEG moiety, and both are degraded separately by different groups of bacteria (Steber and Wierich 1985). In the absence of oxygen, fermentative degradation by e.g. P. venetianus starts at the terminal hydroxyl group of the PEG moiety, and the lipophilic residue is released. This implies that anaerobic degradation requires transport of the tenside molecule into the cytoplasm, and of the remnant lipophilic moiety out of the cell. These transport problems necessarily restrict the range of tenside degradation under anaerobic conditions, whereas in the presence of oxygen the primary cleavage of lipophilic and hydrophilic residues separates the individual degradation problems of the two fractions.

Acknowledgements. The authors are indebted to Prof. Dr. Norbert Pfennig for financial support and valuable criticism. This study was supported by research grants of the Fakultät für Biologie der Universität Konstanz, West Germany.

\section{References}

Abeles RH (1966) Dioldehydrase. Colowick SP, Kaplan NO (eds) Academic Press, New York, London. Meth Enzymol 9:686-689

Barker HA (1972) Corrinoid-dependent enzymic reactions. Annu Rev Biochem 41:55-90

Bock KH, Stache H (1982) Surfactants. In: Hutzinger O (ed) The handbook of environmental chemistry. Springer, Berlin, Vol. 3 B: 163-199

Cox DP (1978) The biodegradation of polyethylene glycols. Adv Appl Microbiol 23:173-194

Dwyer DF, Tiedje JM (1983) Degradation of ethylene glycol and polyethylene glycols by methanogenic consortia. Appl Environ Microbiol 46:185-190

Grant MA, Payne WJ (1983) Anaerobic growth of Alcaligenes faecalis var. denitrificans at the expense of ether glycols and nonionic detergents. Biotechnol Bioeng 25:627-630

Haines JR, Alexander M (1975) Microbial degradation of polyethylene glycols. Appl Microbiol 29:621-625
International Union of Biochemistry (ed) (1984) Enzyme Nomenclature 1984. Academic Press, New York

Kawai F (1985) Existence of ether bond-cleaving enzyme in a polyethylene glycol-utilizing symbiotic mixed culture. FEMS Microbiol Lett 30:273-276

Kawai F, Kimura T, Tani Y, Yamada H, Ueno T, Fukami H (1983) Identification of reaction products of polyethylene glycol dehydrogenase. Agric Biol Chem 47:1669-1671

Kawai F, Kimura T, Tani Y, Yamada H (1984) Involvement of a polyethylene glycol (PEG) - oxidizing enzyme in the bacterial metabolism of PEG. Agric Biol Chem 48:1349-1351

Kuenen JG, Veldkamp H (1972) Thiomicrospira pelophila nov. gen., nov. sp., a new obligately chemolithotrophic colourless sulfur bacterium. Antonie van Leeuwenhoek $38: 241-256$

Payne WJ, Todd RL (1966) Flavin-linked dehydrogenation of ether glycols by cell-free extracts of a soil bacterium. J Bacteriol 91:1533-1536

Pearce BA, Heydeman MT (1980) Metabolism of di(ethyleneglycol)(2-(2'-hydroxyethoxy) ethanol) and other short Poly(ethylene glycol)s by Gram-negative bacteria. J Gen Microbiol 118:21-27

Schink B (1985) Fermentation of acetylene by an obligate anaerobe, Pelobacter acetylenicus sp. nov. Arch. Microbiol 142:295-301

Schink B, Pfennig N (1982) Fermentation of trihydroxybenzenes by Pelobacter acidigallici gen. nov. sp. nov., a new strictly anaerobic, non-sporeforming bacterium. Arch Microbiol 133: 195-201

Schink B, Stieb M (1983) Fermentative degradation of polyethylene glycol by a new, strictly anaerobic, Gram-negative, non-sporeforming bacterium, Pelobacter venetianus sp. nov. Appl Environ Microbiol 45:1905-1913

Schütz H, Radler F (1984) Propanediol - 1,2-dehydratase and metabolism of glycerol of Lactobacillus brevis. Arch Microbiol 139:366-370

Steber J, Wierich P (1985) Metabolites and biodegradation pathways of fatty alcohol ethoxylates in microbial biocoenoses of sewage treatment plants. Appl Environ Microbiol 49:530-537

Stevenson DG (1954) The absorptiometric determination of a nonionic detergent. Analyst 79:504-507

Stouthamer AH (1979) The search for correlation between theoretical and experimental growth yields. In: Quayle JR (ed) International Review of Biochemistry, Microbial Biochemistry. Vol. 21, University Park Press, Baltimore, pp $1-47$

Thélu J, Medina L, Pelmont J (1980) Oxidation of polyoxyethylene oligomers by an inducible enzyme from Pseudomonas P400. FEMS Microbiol Lett 8:187-190

Toraya T, Fukui S (1982) Diol Dehydrase. In: Dolphin D (ed) $B_{12}$, Vol. 2, John Wiley and Sons, New York, pp 233-262

Watson GK, Jones N (1977) The biodegradation of polyethylene glycols by sewage bacteria. Water Res 11:95-100 